\title{
Stress Protein Expression in Bladder Tumors Tissues
}

\author{
Hind M. Mousa" ‘Amna N. Jassem ${ }^{* *}$ ، Munther J. Hussain ${ }^{* * *}$ \\ * Pathological analysis department ,faculty of science ، Thi-Qar university. \\ ***Bology Department, College of Science for Women, Baghdad University . \\ **** Institute of Liver Studies, King's College London School of Medicine at King's College \\ Hospital, London SE5 9RS, UK. E-mail : Hindmousa155@yahoo.com
}

\begin{abstract}
This study was designed to compare between the stress protein HSP70 immunoexpression in the urinary bladder cancer (UBC) and bladder benign tumor (BT), and to show the association between its immunoexpression and the clinical grades in bladder cancer. Paraffin Sections tissues from 50- bladder cancer tissues and 15-bladder benign tumor tissues included in this study, Immunohistochemical technique was done to detect the immunostaining of stress protein HSP-70. The results indicated that (HSP70) proteins were significantly high expressed in BC compared with BT patients HSP70 (74\% versus $33.3 \% ; \mathrm{p} \leq 0.01)$, and the patients with high grades cancer assume elevated positive IHC results compare to patients with low grades cancer with significant difference $(\mathrm{p} \leq 0.01)$. Accordingly,HSP70 can be investigated as an omen biomarker in bladder cancer .
\end{abstract} Key Words: HSP70, IHC, Bladder Tumors.

\section{Introduction:}

Heat shock proteins (HSPs) are stress proteins that are released and activated as a result for natural stress such as fever and, or artificial stressors, like sudden higher temperature and chemotherapy [1]. There are several types of HSPs such as Hsp60, Hsp70 and Hsp90 (the most widely studied HSPs) [2] . They act as a 
chaperone play a big role in proteins interaction with each others like protein conformation, protection from assembly damage proteins. HSPs promote inflammation process through transcription and release cytokines to give dangers sign [3] .

Also these proteins have a crucial role in many human cancers, it is suspected to have role in cancer cells proliferation, differentiation and aggressive metastasis in addition to their role as anti-apoptosis proteins on many steps of this process[2],[3] . HSP70s is the most indispensable HSPs for protein folding and is highly associated with tumor advancement, which may also supply therapeutic strategy of cancer [4] .

HSP70 is marginally expressed in normal cells, but is over expressed in malignancy cells, and in general hopeless prognosis, increased tumor grade and drug resistance of various cancers are related with elevated levels of this protein [5],[6] .

So the goal of this Study to detect the significant biological association between bladder carcinoma (BC) and protein tissue expression of HSP70 as a diagnostic biomarker marker in Iraqi patients with BC by using Immunohistochemical technique (IHC) with HSP70 -monoclonal antibody .

\section{Material \& Methods}

Fifty biopsies from patients with urinary bladder carcinoma (UBC) were included in this study, the patient samples were collected from AL-Yarmook Teaching Hospital and Gazii AL-Harriri Hospital for Specialists Surgeries. The diagnosis of these tissue blocks were primarily based on the obtained histopathological records of bladder biopsy samples in hospital laboratory. Confirmatory histopathological re evaluation of each obtained tissue blocks was performed by specialist pathologist. In addition 15 biopsies from patients with 
bladder benign tumor (BT) . For each case, one representative section was stained with Hematoxylin and Eosinand the histopathological diagnosis was revised, while other sections wereput on positive charged slides and stained immunohistochemically for HSP70. Immunohistochemical staining was carried out using the Novocastra TM Polymer Detection Systems (Envision technique) by using commercial kit from Novocastra, Newcastle, UK, RE7150-K, the slides were deparaffinized, rehydrated then antigen retrieval carried out by placing the slide in slide steel holder and it was immersed in $1 \mathrm{~L}$ of Tris - EDTA buffer $\mathrm{pH}=9$, in plastic container, it was placed in microwave at $(800 \mathrm{~W})$ for 10 minutes. After cooling the antigen retrieval solution for $15-20$ minutes at $\left(4^{\circ} \mathrm{C}\right)$, the slides were removed and washed by PBS, after that the slides were blocked with peroxides blocking and protein blocking. All of the slides were treated with Monoclonal mouse Antihuman HSP70 monoclonal antibody, dilution1:400 (Dako, Denemark), then incubated with a post primary block solution for 30 minutes. In the next step the slides were rinsed gently in PBS $2 \times 5$ and tissue sections incubated with a secondary antibody Novolink TM polymer mouse and rabbit immunoglobulins) for 30 minutes, washed in PBS $2 \times 5$ with gentle rocking. After washing, the samples were stained with diluted liquid $\mathrm{DAB}$, and then counter stained with hematoxylin. Slides washed, dehydrated then mounting, and examining under light microscope at 10X,20X,40X magnification. 


\section{Results \& Discussion}

At the current time, only few Iraqi studies have been focused on HSP expression in UBC. The last two decades, studies that have determined HSPs expression mostly focused on Western blot, mRNA expression and ELISA. The first two tests are costly and time consuming, while the latter is not specific. Thus, IHC for HSP appears to be feasible in the hospitals for detecting UBC.

In this study the positive immunohistochemical expression of HSP70 protein was significantly higher in UBC patients in comparison with that of BT patients (74\% versus $33.3 \% ; \mathrm{p} \leq 0.01$.), (Table 1). These results compatible with Syrigos et al. (2003) who assume that HSP70 was often overexpressed in vesical tumoral cells of bladder than control [7]. The bladder epithelia showed intense staining of HSP70 (Figure 1), and also it was found in all layers of bladder transitional epithelium . Our results corresponds with the data postulated that HSPs may suppress program death and thus promote tumorigenesis [8] .

Table (1): HSP70 expression in bladder patients groups

\begin{tabular}{|c|c|c|c|c|c|c|}
\hline \multirow{2}{*}{\multicolumn{2}{|c|}{ Patients groups }} & \multicolumn{2}{|c|}{ HSP70 immunostaining } & \multirow{2}{*}{ Total } & \multirow{2}{*}{$\begin{array}{l}\text { Chi- } \\
\text { square }\end{array}$} & \multirow{2}{*}{$P$ value } \\
\hline & & positive & negative & & & \\
\hline \multirow{2}{*}{ UBC } & No & 37 & 13 & 50 & \multirow{6}{*}{8.346} & \multirow{6}{*}{0.00393} \\
\hline & Percentage \% & 74 & 26 & 100 & & \\
\hline \multirow{2}{*}{ BT } & No & 5 & 10 & 15 & & \\
\hline & Percentage \% & 33.3 & 66.7 & 100 & & \\
\hline \multirow{2}{*}{ Total } & No & 42 & 23 & 65 & & \\
\hline & Percentage\% & 64.6 & 35.4 & 100 & & \\
\hline
\end{tabular}

In terms of scores, UBC patients with the score ++ represented the highest frequency (48.6\%), and a similar observation was made in BT patients but the frequency was higher $(60 \%)$. However, (Table 2) showed the frequency 
distribution of HSP70 expression scores in group subjects. Chi-Square test showed that there was significant difference $(\mathrm{p} \leq 0.01)$ between urinary bladder carcinoma and bladder benign tumor for HSP70 IHC scores in tissue sample taken from each case. Regarding the tumor grade of UBC, HSP70 was detected in 10 out of 18 of grade-1, 16 out of 19 of grade-2, and 11 out of 13 of grade-3. There was a high significant association between the grade of UBC and the immunohistochemical expression of HSP70 ( $p \leq 0.01)$, the majority of high grade tumor cases showed positive immunohistochemical HSP70 expression 27(84. 4\%), while only 10 cases (55.6\%) of low grade tumor showed positive immunohistochemical HSP70 expression, (Table 3).

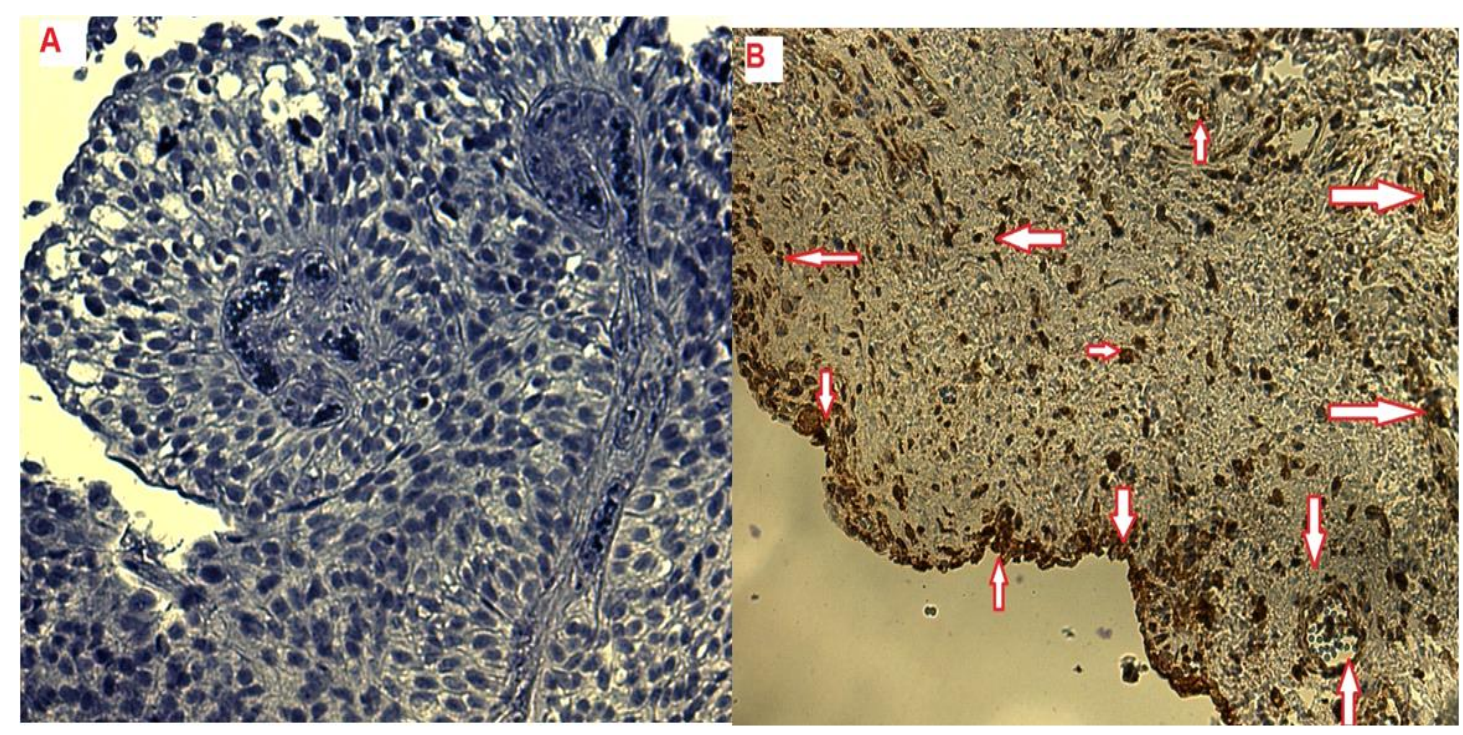

Figure( 1): A: Immunohistochemical tissue expression of HSP70 in bladder tissues showing no detectible HSP70 immunostaining (score 0 negative). B: Showing strong positive HSP70 immunostaining in bladder epithelia (Score ++ brown) ( arrow) (20X). 


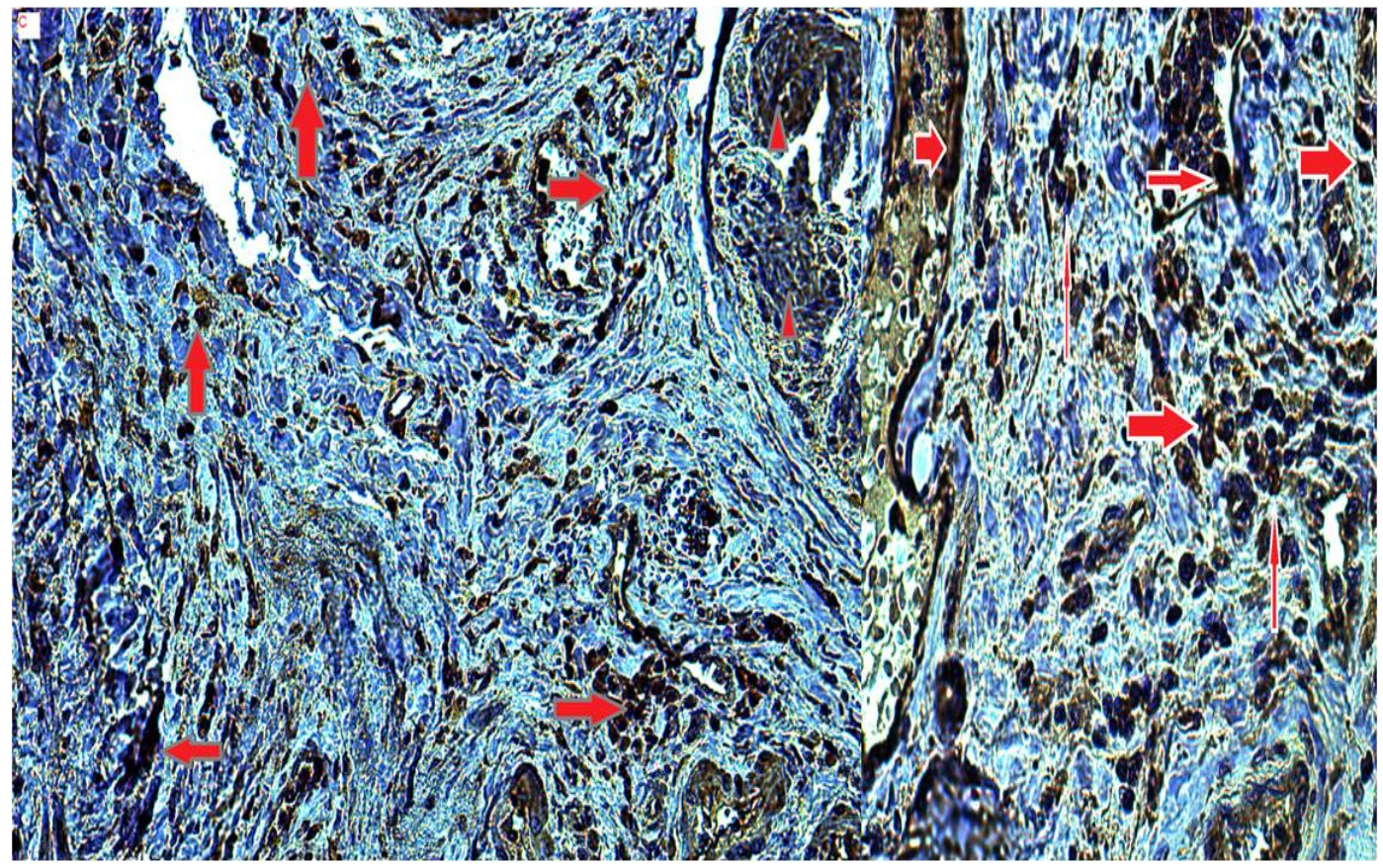

Figure( 1 ): C: Invasive transitional cell carcinoma , poorly differential(Grade II) showing positive HSP70 immunostaining (Score +++ brown)( arrow) (20X,40X) .

Table (2): Frequency of HSP70 IHC scores in patients groups

\begin{tabular}{|ccccccc|}
\hline \multirow{2}{*}{ HSP70 Score } & \multicolumn{2}{c}{ UBC } & \multicolumn{2}{c}{ BT } & \multicolumn{2}{c|}{ Total } \\
\cline { 2 - 7 } & No. & $\%$ & No. & $\%$ & No. & $\%$ \\
\hline+++ & 11 & 29.7 & 0 & 0 & 11 & $\mathbf{2 6 . 2}$ \\
\hline++ & 18 & 48.6 & 3 & 60 & 21 & $\mathbf{5 0}$ \\
\hline+ & 8 & 21.6 & 0 & 0 & 8 & $\mathbf{1 9}$ \\
\hline Scatter $\leq \mathbf{1 0}$ & 0 & 0 & 2 & 40 & 2 & $\mathbf{4 . 8}$ \\
\hline Total & 37 & 88.1 & 5 & 11.9 & 42 & $\mathbf{1 0 0}$ \\
\hline P-value & -- & $\mathbf{0 . 0 0 6}$ & -- & $\mathbf{0 . 0 0 1 2}$ & -- & $\mathbf{0 . 0 0 2}$ \\
$\chi 2-$ value & & $\mathbf{7 . 5 1 9}$ & & $\mathbf{1 0 . 8 5} * *$ & & $\mathbf{8 . 9 2 8}$ \\
& & $* *$ & & & & $* *$ \\
\hline
\end{tabular}

$* *(\mathrm{P}<0.01)$. High significant

An increased expression of HSP70 has been reported in a number of tumours, such as osteosarcoma bladder cancer [7],[9]. The patients with cancer have high levels of HSPs that are associated with poor prognosis , and treatment resistance as 
these proteins protect tumour cells from therapeutic stressors such as androgen or oestrogen withdrawal, radiation, metastases, and cytotoxic chemotherapy [10],[11].

In this study our results are in correspondence with the study results of Cappello 'et al. (2006) who demonstrated a significant association of the high grades $(G \geq 2)$ of UBC with the percentage of tumor cells positive HSP70 [12]. Syrigos et al. (2003) investigated the expression of HSP70 in a series of UBC, finding that this protein was extremely expressed in advanced grades of bladder cancer and assume its function as biomarker [7]. Moreover, other published studies confirm a relation between high HSP-70 expression and tumor aggressiveness and propagation [13]. HSP-70 is proposed to inhibit the energizing of caspases, crossing apoptosis and thus allowing a survival reward of transformed cell [14].

\section{Conclusion}

The high significant differences in the IHC expression score of HSP70 in BC compared with BT and elevated expression in patients with high grades of UBC have led to HSP70 being investigated as a prognostic biomarker in bladder cancer .

Table (3 ) Association between HSP70 IHC expression with tumor grade

\begin{tabular}{|c|c|c|c|c|c|}
\hline \multirow{2}{*}{\multicolumn{2}{|c|}{ parameter }} & \multicolumn{2}{|c|}{ HSP70 EXPRESSION } & \multirow[t]{2}{*}{ Total } & \multirow{2}{*}{$\begin{array}{l}\mathrm{P} \text {-value } \\
\chi^{2} \text {-value }\end{array}$} \\
\hline & & positive & negative & & \\
\hline \multirow[t]{3}{*}{$\begin{array}{c}\text { Grade of } \\
\text { UBC }\end{array}$} & $\begin{array}{c}\text { Low grade } \\
(\mathbf{G} \leq 1)\end{array}$ & $10(55.6 \%)$ & $8(44.4 \%)$ & 18 & \multirow{3}{*}{$\begin{array}{c}0.0025 \\
7.418 * *\end{array}$} \\
\hline & $\begin{array}{l}\text { High grade } \\
\quad(G \geq 2)\end{array}$ & $27(84.4 \%)$ & $5(15.6 \%)$ & 32 & \\
\hline & Total & $37(74 \%)$ & $13(26 \%)$ & 50 & \\
\hline \multicolumn{6}{|c|}{$* *(\mathrm{P} \leq 0.01)$ high significant } \\
\hline
\end{tabular}




\section{References}

1. Goldstein M.G. and Li, Z . Heat-shock proteins in infection-mediated inflammation-induced tumorigenesis . J Hematol Oncol . 2009; 2:(5):1-10.

2. Jego G., Hazoumé A., Seigneuric R., and Garrido C.. Targeting heat shock proteins in cancer. Cancer Lett. 2013; 332(2):275-285 .

3. Trivedi V., Gadhvi P.; Chorawala M., Shah G. Role of Heat shock Proteins in immune response and immunotherapy for human cancer. Int J Pharm Sci Rev Res, Gandhinagar. 2010 ; 382 023. 2( 2): 57-62 .

4. Murphy E.M . The HSP70 family and cancer. Carcinogenesis J. 2013; 34 (6 ):1181-1188.

5. Balaburski, G. M, Ju Leu J., Beeharry N., Hayik S., . Andrake M. D, Zhang G , Herlyn M., . Villanueva J,1 Dunbrack, Yen T., George D. L., and Murphy1, M. E. A modified HSP70 inhibitor shows broad activity as an anticancer agent . Mol Cancer Res . 2013 ;11(3): 219-229.

6. Powers, M.V., Jones, K., Barillari C. , West wood I. , van Montfort R.L., and Workman P.Targeting HSP70: the second potentially druggable heat shock protein and molecular chaperone? J. Cell Cycle. 2010 ;9:1542-50.

7. Syrigos KN, Harrington KJ, Karayiannakis AJ, Sekara E, Chatziyianni E. Syrigou EI, and Waxman J . Clinical significance of heat shock protein-70 expression in bladder cancer. Urology J . 2003 ; 61: 677-680

8. Garrido C., Gurbuxani S, Ravagnan L., and Kroemer G. Heat shock proteins: endogenous modulators of apoptotic cell death. Biochem Biophys Res Commun . 2001; 286: 433-442. 
9. Moalic-Juge S, Liagre B, Duval R, Corbiere C, Bianchi A, Bordji K, Bosgiraud C, and Beneytout JL.The anti-apoptotic property of NS-398 at high dose can be mediated in part through NF- $\mathrm{KB}$ activation, hsp70 induction and a decrease in caspase-3 activity in human osteosarcoma cells. Int J Oncol . 2002; 20: 1255-1262.

10. Cornford PA, Dodson AR, Parsons KF, Desmond AD, Woolfenden A, Fordham M, Neoptolemos JP, Ke Y, and Foster CS.. Heat shock protein expression independently predicts clinical outcome in prostate cancer. Cancer Res . $2000 ; 60$ : 7099-7105 .

11. Ischia J. and So A. I . The role of heat shock proteins in bladder cancer. Nat. Rev. Urol. 2013 ; 10, 386-395

12. Cappello F., David S., Ardizzone N., Rappa F., Marasà L., Bucchieri F., and Zummo G.. Expression of Heat Shock Proteins HSP10, HSP27, HSP60, HSP70, and HSP90 in Urothelial Carcinoma of Urinary Bladder. J. Cancer Mol . 2006; 2(2): 73-77

13. Thanner F, Sutterlin MW, and Kapp M. Heat-shock protein 70 as a prognostic marker in node-negative breast cancer. Anticancer Res . 2003 ; 23: 1057-62.

14. LeBlanc A.C .Natural cellular inhibitors of caspases. ProgNeuropsychopharmacol Biol Psychiatry . 2003 ; 27: 215-29. 
